DOI: https://doi.org/10.11144/Javeriana.umed61-4.fmrp

\title{
FMRP y las neuroliginas: la influencia de la actividad sensorial en las dinámicas del neurodesarrollo
}

\section{FMRP and Neuroligins: The Influence of Sensory Activity on Neurodevelopment Dynamics}

Recibido: 23 Diciembre 2019 | Aceptado: 13 Abril 2020

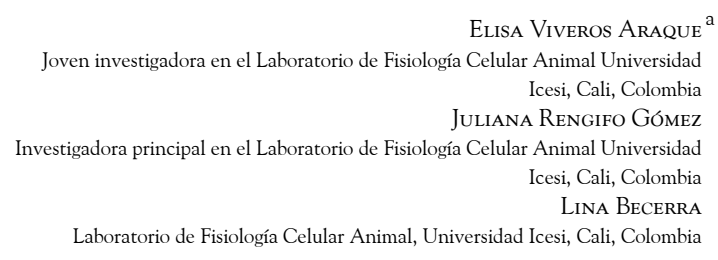

a Autora de correspondencia: elisaviverosaraque@outlook.com

RESUMEN

En el periodo crítico del desarrollo, acontecido en etapas posnatales, se remodelan las sinapsis establecidas. Este proceso es dependiente de la actividad eléctrica generada por la entrada de estímulos sensoriales que los organismos experimentan. La proteína asociada al retardo mental frágil $\mathrm{X}(\mathrm{FMRP})$ es una proteína reguladora de la traducción de ARNm que participa en dichas remodelaciones durante este periodo. Las fallas en su función coinciden con la aparición de espinas dendríticas inmaduras, circuitos neuronales sobreabundantes y con pérdida de plasticidad. Las neuroliginas, por su parte, son proteínas de adhesión neuronal postsináptica que ayudan a la especialización y la maduración dendrítica, y su mutación coincide con alteraciones en la transmisión sináptica. La FMRP y las neuroliginas son proteínas reguladas por la experiencia sensorial y son necesarias para los procesos de eliminación y maduración sináptica, respectivamente. Las fallas en su expresión se relacionan con el síndrome de frágil X y los trastornos del espectro autista, que pueden provocar importantes problemas cognitivos y conductuales. En esta revisión se examinan los principales hallazgos sobre estas proteínas, su relación y su modulación dependiente de la actividad a través del desarrollo. Además, destacamos la Drosophila melanogaster como un organismo modelo de las emergentes investigaciones en este campo.

Palabras clave

desarrollo dependiente de actividad; proteína de retardo mental del cromosoma X frágil (FMRP); neuroliginas; autismo; síndrome de frágil X (SFX).

Cómo citar: Viveros Araque E, Rengifo Gómez J, Becerra L. FMRP y las neuroliginas: la influencia de la actividad sensorial en las dinámicas del neurodesarrollo. Univ. Med. 2020;61(4). https://doi.o $\mathrm{rg} / 10.11144 /$ Javeriana.umed61-4.fmrp

\begin{abstract}
In the critical period of development, occurring in postnatal stages, established synapses are remodeled. This process is dependent on the electrical activity generated by the input of sensory stimuli that organisms experience. The Fragile $\mathrm{X}$ mental retardation protein (FMRP) is a mRNA translational regulatory protein that participates in the synapses remodeling process, during this period. Failures in its function coincide with the appearance of immature dendritic spines, overabundant neural circuits, and loss of plasticity. Neuroligins, for their part, are postsynaptic neuronal adhesion proteins that assist dendritic specialization and
\end{abstract}


maturation, and their mutation coincides with alterations in synaptic transmission. FMRP and neuroligins are proteins regulated by sensory experience and necessary for of synaptic elimination and maturation processes, respectively. Failures in its expression are related to Fragile X syndrome and Autism Spectrum Disorders that can cause significant cognitive and behavioral problems. In this review we examine the main findings on these proteins, their relationship, and their activitydependent modulation through development. In addition, we highlight Drosophila melanogaster as a model organism for emerging research in this field.

Keywords

activity-dependent development; fragile $\mathrm{X}$ mental retardation protein (FMRP); neuroligins; autism; fragile X syndrome (SFX).

\section{Introducción}

La sinaptogénesis o construcción de sinapsis tiene su apogeo en etapas tempranas del desarrollo del embrión; entre tanto, en la etapa posnatal, conocida como periodo crítico, unas sinapsis se fortalecen y maduran mientras otras no se conservan. La eliminación de sinapsis, conocida como poda sináptica, es necesaria para las sinapsis inapropiadas o aquellas cuya maduración no se estimuló por falta de actividad, tornándose ineficaces. Varios trastornos del neurodesarrollo, incluidos los trastornos del espectro autista (TEA) y el síndrome del frágil X (SFX), coinciden en presentar afecciones en el periodo crítico del desarrollo neuronal, con conexiones sinápticas que se constituyen defectuosamente, transmisión sináptica poco modulada, un desbalance entre señales excitatorias e inhibitorias y alteración en los sistemas de plasticidad sináptica (1).

Existe un grupo de proteínas que participan activamente en el crecimiento y extensión de las neuritas, así como en su diferenciación y en el establecimiento final de contactos sinápticos maduros. Dada su relevancia funcional, su estrecha relación funcional y sus implicaciones en el contexto clínico de patologías del desarrollo, la proteína asociada al retardo mental frágil X (FMRP) y las proteínas neuroliginas $(\mathrm{Nlg})$ se revisan en el presente artículo. Cabe destacar que estos dos grupos proteicos están relacionados con la actividad sensorial inducida por la experiencia, de la cual son dependientes durante los periodos críticos posnatales.
Las funciones de la proteína FMRP, cuya síntesis se ve afectada en el SFX, incluyen el transporte del ARN mensajero (ARNm) a la sinapsis desde el soma, e incluso desde el núcleo y la regulación de la síntesis de proteínas implicadas en el ensamblaje y funcionamiento de las sinapsis, ya sea por unión a sus transcritos o por bloqueo a las subunidades ribosomales que los traducen (2). Los defectos en la expresión de la FMRP coinciden con la presencia de circuitos neuronales aberrantes, ya que hay demasiadas sinapsis, muchas de ellas inmaduras y con una morfología anormal, con sobreproducción de proteínas y con toxicidad causada por acumulación de ARNm (3).

Las Nlg, por otro lado, son proteínas de adhesión celular que, además de conectar en la sinapsis las membranas de las dos neuronas, ayudan a consolidar las conexiones neuronales que se forman con la experiencia sensorial (4). En el TEA se han detectado mutaciones en la proteína Nlg que afectan la citoarquitectura funcional de la sinapsis con implicaciones en la actividad de las conexiones neuronales (1). Existen estudios que relacionan la ausencia de la FMRP con la expresión anormal de Nlg1 y con déficits en el comportamiento social en ratones, y hay estudios in vitro de inmunoprecipitación que han encontrado la FMRP unida al ARNm de la Nlg $2(5,6)$. Sin embargo, aún falta mucho por entender sobre las bases moleculares de este vínculo y su posible conexión en el desarrollo de estas enfermedades.

\section{Sinaptogénesis, poda sináptica $\mathrm{y}$ eliminación dependiente de actividad}

El desarrollo del sistema nervioso es un proceso complejo que inicia con la proliferación de las células neuronales y su migración a posiciones particulares. A este primer proceso complejo, le sigue la etapa de la sinaptogénesis en la que, usando el cono de crecimiento axónico, la neurona busca y reconoce su dendrita objetivo. La sinaptogénesis se divide en la fase inicial de reconocimiento, donde hay un contacto superficial entre las dos neuronas; la fase inductiva, donde 
por medio de proteínas de adhesión celular se afianza esta unión; la fase de especialización, donde gracias a la activación de cascadas de señalización celular se diferencia la membrana postsináptica de la presináptica y se define la sinapsis como excitatoria o inhibitoria, y la fase de maduración, donde se consolida la expresión de las todas proteínas necesarias en la sinapsis, como las proteínas necesarias para la exocitosis de las vesículas con los neurotransmisores, las proteínas que reclutan los receptores sinápticos y las proteínas de soporte del citoesqueleto $(7,8)$.

Sin embargo, durante el desarrollo del sistema nervioso no todas las sinapsis formadas llegarán a la fase de maduración; muchas iniciarán la fase de eliminación. Se cree que la experiencia sensorial y la actividad eléctrica que esta produce en los circuitos neuronales es determinante en el momento de seleccionar cuáles sinapsis maduran y cuáles se eliminan. Los circuitos neuronales que se activaron al captar una experiencia se hacen más fuertes y tienden a crear más conexiones sinápticas; mientras que aquellas sinapsis que no se usaron o que fueron generadas en puntos incorrectos se hacen más débiles y se eliminan $(7,8)$.

En los animales, el refinamiento o remodelación de los circuitos neuronales generado por estos procesos de eliminación o poda sináptica y cimentación de nuevas conexiones se maximiza en la ventana del desarrollo que corresponde con el periodo posnatal (que en humanos corresponde a la niñez y a la adolescencia) y se reduce drásticamente cuando se llega a la madurez (9). Aunque los mecanismos moleculares encargados de eliminar una sinapsis (ya sea porque es incorrecta o porque no se usó para alguna actividad) aún no están totalmente entendidos, si hay evidencia que implica directamente a la proteína FMRP en el proceso (10).

A lo largo de la vida de los animales, las sinapsis que no se eliminaron y que, por el contrario, maduraron pueden cambiar la fortaleza de su respuesta eléctrica dependiendo de la experiencia obtenida en la interacción con el ambiente. A esto se le llama plasticidad neuronal $(1,11,12)$. Las dos formas principales de plasticidad sináptica en el cerebro son la potenciación a largo plazo (LTP) y la depresión a largo plazo (LTD) (13).

La LTD es el mecanismo dependiente de actividad por el cual se eliminan algunas sinapsis. Ocurre especialmente cuando la membrana postsináptica es estimulada con baja intensidad durante largos periodos o cuando el potencial de acción de la neurona presináptica ocurre después de que inicie el potencial postsináptico excitador (EPSP) (14). Independientemente de la razón, este mecanismo es sobre todo glutamatérgico. $\mathrm{Al}$ unirse el glutamato a los receptores ionotrópicos AMPA, estos abren el poro de su canal y permiten la entrada de cationes de sodio y potasio $\left(\mathrm{Na}^{+} \mathrm{y}\right.$ $\mathrm{K}^{+}$) a la neurona postsináptica, despolarizándola e incitando a que los receptores ionotrópicos NMDA se desbloqueen del ion magnesio $\left(\mathrm{Mg}^{+2}\right)$ que obstruye el poro de su canal $(15,16)$. Este desbloqueo de los receptores NMDA permite un influjo de iones de $\mathrm{Na}^{+}$, especialmente de calcio $\left(\mathrm{Ca}^{+2}\right)$, el cual es importante para los procesos de plasticidad sináptica, aprendizaje y memoria, ya que de la cantidad de $\mathrm{Ca}^{+2}$ ingresado depende tanto la magnitud de la señal eléctrica recibida como la temporalidad del potencial de acción recibido por la membrana presináptica (si este potencial presináptico precede o, por el contrario, sigue al EPSP) $(17,18,19)$.

Si el EPSP es fuerte y ocurre después de la despolarización de la membrana presináptica, la concentración de $\mathrm{Ca}^{+2}$ dentro de las células será suficiente para activar ciertas cinasas que ayudarán a que se transloquen en la membrana más receptores AMPA con más permeabilidad, lo que aumenta la señal eléctrica y, por lo tanto, vuelve más fuerte aquellas sinapsis, un proceso denominado LTP. Por el contrario, si el potencial de acción recibido es débil y muy frecuente o el EPSP ocurre antes de la activación del potencial de acción presináptico, el influjo de $\mathrm{Ca}^{+2}$ recibido es poco y no activará cinasas, sino más bien fosfatasas que provocarán la internalización, por endocitosis, de los receptores AMPA, lo que trae como consecuencia que, cada vez más, la membrana postsináptica sea menos 
sensible al glutamato y su estimulación sea más difícil, proceso que corresponde al LTD $(14,15$, $16,17,18,19)$.

Adicionalmente, para la LTD existe otro mecanismo que no es mediado por receptores NMDA, sino por los receptores metabotrópicos de glutamato mGluR, en especial los receptores 1 y 5 . Por lo general, la estimulación prolongada de estos receptores conduce a la cascada de acople a la proteína $G$ trimérica, que lleva a la activación de la proteína fosfolipasa C (PLC), a la producción de 1,4,5-trifosfato de inositol y a la liberación de $\mathrm{Ca}^{+2}$ intracelular (15). Las señales de $\mathrm{Ca}^{+2}$ activan las proteínas cinasas que se translocan a la densidad postsináptica y activan la traducción de proteínas como las Step, Map1b, Arc y APP que, a su vez, promueven la internalización de los receptores AMPA. Las cascadas de señalización más estudiadas para la LTD son la ERK $1 / 2$ y la mTOR, las cuales llevan al aumento de traducción de proteínas para la internalización de los receptores AMPA o activan su proteólisis por calpaína. También se ha visto implicada en este fenómeno la vía Ras-MEK-JNK, que lleva a la activación de factores de transcripción. Por último, cuando estas vías llevan a la internalización de receptores ionotrópicos de glutamato mediada por mGluR, el proceso es prácticamente irreversible, lo que lleva a la eliminación indefectible de la sinapsis afectada $(18,19)$. Interesantemente, la función de la FMRP en el transporte del ARNm a las sinapsis y en la regulación negativa de la traducción la posiciona como una proteína con capacidad moduladora de las cascadas de señalización que participan tanto en la fase de maduración como en la poda o fase de eliminación de las sinapsis (20).

\section{Proteína de retardo mental asociada a frágil X}

La FMRP es una proteína de unión al ARNm que participa en su transporte y estabilización desde el núcleo al citoplasma, del citoplasma a la región sináptica y que, además, controla negativamente la traducción de estos (21). Dicha proteína se encuentra en todos los tejidos del cuerpo, pero sobreabunda en los tejidos cerebrales y en los testículos y ovarios. En las células, la mayoría de esta proteína se encuentra en el citoplasma, aunque una parte de ella se ubica en el núcleo. La FMRP es expresada altamente en las neuronas, pero también se puede encontrar en astrocitos, oligodendrocitos y en la microglía (22). Tanto en murinos como en Drosophila, así como en los humanos, esta proteína tiene varias isoformas, lo que da cuenta de su versatilidad en cada uno de los tejidos (23).

La FMRP posee en su estructura varios dominios de unión al ARNm: dos dominios Tudor (que también están implicados en las interacciones proteína-proteína), dos dominios $\mathrm{KH}$ y un dominio RGG. Gracias a estos, la FMRP se puede unir a las estructuras secundarias que forman sus ARN diana. Por ejemplo, se describe que se une a la región G-quadruplex de los ARNm de una manera tridimensional o que sus dominios pueden interactuar con las regiones ricas en uracilo, según algunos autores $(23,24)$. Otras interacciones que se predicen para los dominios $\mathrm{KH}$, que se han demostrado solamente in vitro, son la asociación de la FMRP a las estructuras de bucle y a algunas horquillas de ARN denominadas kissing, stem-loop $(23,24,25)$.

Este tipo de uniones directas de FMRP con el ARNm no son las únicas que se plantean como el mecanismo por el cual la FMRP es capaz de bloquear la traducción de transcritos. Se ha propuesto que la unión de la FMRP a las estructuras secundarias del ARNm, además de ayudar a estabilizarlo, puede generar un impedimento estérico para que sea traducido por polirribosomas en la fase de elongación. También se ha postulado que la FMRP puede impedir físicamente la unión de los factores iniciadores de la traducción del ARNm a la caperuza 5-prima $(23,24)$.

Adicionalmente, se ha descubierto que la FMRP puede unirse directamente a los ribosomas y detener la traducción del transcrito que están llevando a cabo. En este caso, se ha propuesto que la FMRP bloquea la iniciación, el alargamiento de la traducción y la translocación ribosomal, uniéndose a la subunidad 80 S $(21,25,26)$. La 
FMRP también puede disminuir la traducción de las proteínas al unirse con micro-ARN y estimular la formación del complejo de silenciamiento inducido, el cual cumple con silenciar el ARNm diana. Este tipo de regulación negativa de la traducción se da para los transcritos de NR2A, que es una subunidad del receptor NMDA, y para los transcritos de la proteína PSD-95 $(27,28)$.

Se ha postulado que la FMRP también inhibe la traducción de ciertos ARNm de manera indirecta, al unirse a proteínas reguladoras de la inhibición de la traducción. La proteína citoplasmática 1 de interacción con FMRP (CYFIP) es uno de estos reguladores. El complejo CYFIP-FMRP se une al factor de iniciación de la traducción eucariota 4E (eIF4E) e impide su ensamblaje con los demás factores de iniciación de la traducción $(23,24,29)$.

Además de estas funciones en el citoplasma y las dendritas, la proteína FMRP también tiene funciones en el núcleo y se ha demostrado que las isoformas 6 y 12 se localizan en los cuerpos de Cajal en cultivo de células humanas (30). La proteína FMRP tiene una señal de exportación de núcleo y se une a la proteína factor de exportación de ARN nuclear Tap/NXF1, lo que le permitiría hacer el transporte extranuclear de los transcritos y una función de chaperona en el exporte de ARNm al citoplasma (31). Otros estudios describen la unión de la FMRP a la cromatina como respuesta a daños en el ADN, a través de la unión de su dominio Tudor a las histonas, postulándola incluso como una proteína prosupervivencia en células HeLa (32).

La FMRP también es modulable por modificaciones postraduccionales como fosforilación, metilación, N-glicosilación o amidación (33). La fosforilación de la FMRP la realizan varias cinasas como caseína cinasa-2 (CK2) y la proteína S6 cinasa 1 (S6K1); así mismo, es modulada por la proteína fosfatasa 2 (PP-2), que la desfosforila. La fosforilación en la serina 500 en humanos es necesaria para la unión de esta proteína a los polirribosomas $(25,34,35)$. En cuanto a la metilación, la FMRP tiene regiones ricas en arginina y lisinas, especialmente en los motivos RGG, que son el sustrato potencial de las proteínas arginina metiltransferasas. Se ha observado que al metilarse, la FMRP reduce su capacidad de interacción con el ARNm (36).

Se ha encontrado un pico en la expresión de la FMRP en la ventana del desarrollo dependiente de actividad en el cerebro de ratones y en la cabezas de moscas $(37,38)$ y, consecuentemente, se ha reportado que su activación/inactivación es dependiente de la experiencia sensorial $(21,39)$. Por ejemplo, la FMRP está asociada a los gránulos neuronales que son complejos de proteínas y ARN encargados de llevar los transcritos desde el soma neuronal hasta las dendritas, donde se lleva a cabo la sinapsis. El ARNm transportado en estas estructuras es traduccionalmente silencioso, en el sentido de que su traducción está reprimida en el recorrido y es activada con estímulos neuronales. Se cree que, en el caso de los estímulos glutamatérgicos, la FMRP en estos gránulos es desfosforilada y metilada en su dominio RGG y, por lo tanto, se activa la traducción de los transcritos (40).

Una hipótesis del mecanismo de participación de la FMRP en el refinamiento o remodelación de los circuitos neuronales es que la supresión de la traducción de proteínas (generada por la FMRP) es regulada por la necesidad de la presencia de dichas proteínas en la sinapsis, necesidad que es dependiente de la actividad. En ausencia de la FMRP, podría existir una traducción excesiva y, por lo tanto, una presencia descomunal de proteínas en la sinapsis, que son ineficientes y pueden resultar tóxicas (12). Se ha comprobado que la FMRP regula la traducción de los ARNm que codifican para un gran número de proteínas de la sinapsis como las neurexinas, PSD-95, algunas subunidades de receptores NMDA y AMPA y la proteína asociada a los microtúbulos 1B (MAP1B).

Además, la FMRP regula la traducción de proteínas implicadas en la plasticidad neuronal, como la proteína p0071 (implicada en la modulación del citoesqueleto de la actina) y la proteína TRF2 (cuya función es el transporte de ARNm a axones maduros para promover el crecimiento axonal) (41, 42, 43, 44). La FMRP participa en la activación de la familia de factores de transcripción factores 
potenciadores de miocitos 2, los cuales, vía calmodulina/calmodulina cinasa II, eliminan sinapsis robustamente. También la FMRP modula la producción de proteínas implicadas en la regulación de la LTD, que involucra los receptores metabotrópicos de glutamato (mGluR) 1 y 5, y está relacionada con la plasticidad neuronal, que depende de la síntesis proteica de novo. La ausencia de FMRP, por ejemplo, se ha relacionado con una exagerada LTD en las neuronas glutamatérgicas $(21,45,46)$.

En la LTD mediada por los mGluR se ha postulado que la participación de la FMRP es de vital importancia para explicar los cambios de las espinas dendríticas y de las sinapsis vistos en el SFX y los TEA. Se ha planteado que la estimulación de los receptores de glutamato, por medio de la proteína adaptadora HOMER, inicia la cascada mTOR, la cual incluye la activación de una serie de cinasas (PIKE, PIK3, Akt, mTOR, S6K1). Así, se promueve la fosforilación de la FMRP, activándola y llevando a una disminución en la traducción. Cuando hay mutaciones en la FMRP, hay una excesiva traducción de proteínas incluso cuando mGluR no está activado, por lo que se produce LTD mantenida $(23,47)$. También se ha demostrado que la ERK es desfosforilada rápidamente en ratones $\mathrm{KO}$ para $\mathrm{fmrl}$ cuando los mGluR son estimulados, ya que, al parecer, en ausencia de FMRP se produce una activación aberrante de las fosfatasas. Por ejemplo, la proteína fosfatasa 2 (PP2) y la tirosina fosfatasa están hiperactivas en este tipo de mutación $(48,49)$.

Esta serie de mecanismos moleculares mencionados explican cómo la experiencia sensorial y la actividad eléctrica que esta produce en los circuitos neuronales determinan el estado de activación de la FMRP, una proteína necesaria para generar los cambios dinámicos en el proteoma de la sinapsis que promueven la poda o fase de eliminación de las sinapsis. Por el contrario, cuando hay ausencia de FMRP, se pierde esta capacidad de modulación de la expresión de proteínas en la sinapsis y lleva a una sobreabundancia de espinas dendríticas, las cuales permanecen, en su mayoría, inmaduras y no entran en el proceso de poda sináptica o dendrítica, sino que permanecen en un estado de debilidad que incluso puede tomar morfología filopodial $(20,50)$.

El estudio de las funciones de la proteína FMRP se hizo fundamental para los humanos, con la identificación de la mutación del gen a partir del cual esta se codifica en el SFX, también conocido como el síndrome de MartinBell. Es una enfermedad de gran interés, debido a que 1) representa la segunda causa mundial conocida de discapacidad cognitiva después del síndrome de Down, 2) es la forma más frecuente de discapacidad cognitiva heredada y 3) es la causa genética conocida más común de los TEA $(51,52,53)$.

El SFX es causado por una mutación en el brazo largo del cromosoma X, en la región Xq27.3 en el gen FMR1. Esta mutación consiste en una expansión repetitiva de más de 55 veces del trinucleótido CGG que se encuentran al comienzo de este gen en la región no traducida (UTR) 5' (2). El SFX puede ocurrir también por la deleción parcial o total del gen FMR1. La expansión del trinucleótido puede clasificarse en dos tipos de mutación: las personas que tienen de 55 a 200 repeticiones, quienes presentan una mutación parcial, y aquellas que poseen más de 200 repeticiones y presentan una mutación completa $(54,55,56)$.

Las diferentes manifestaciones clínicas de dicho síndrome están ligadas al número de veces que se reproduce este trinucleótido. Las repeticiones en la premutación — situación de riesgo donde existen expansiones anormales de los tripletes, pero que no causa la enfermedad como tal - permiten fabricar el transcrito del gen FMR1, pero dicho transcrito tiende a acumularse y se traduce muy poco (23). La acumulación de transcritos se vuelve entonces tóxica, ya que estos forman agregados intranucleares en los que pueden estar implicadas varias proteínas de unión a ARN que aumentan su afinidad por estos transcritos al aumentar las repeticiones de CGG $(57,58)$. Las premutaciones de frágil $\mathrm{X}$ producen insuficiencia ovárica primaria, ansiedad, trastorno del sueño y síndrome de ataxia/temblor asociado al frágil X. Por otro lado, el efecto directo de la mutación es la 
no producción de la FMRP, debido a que las repeticiones CGG llevan al bloqueo de la unión de los factores de transcripción, ya sea por la hipermetilación en estas bases o por la conformación errónea de la cromatina $(26,53,59)$.

Esta mutación se transmite a la descendencia siguiendo, más o menos, los patrones de herencia genética de enfermedades ligadas al cromosoma $\mathrm{X}$. Esta alteración de repeticiones trinucleotídica se replica, también, en la gametogénesis de los portadores y se transmite a la descendencia por un mecanismo aún no dilucidado. No obstante, se plantea que la razón por la cual los mecanismos de reparación del ADN no corrigen dichas repeticiones es que estas bases forman estructuras como bucles y horquillas que limitan el acceso a ellas. Durante la meiosis, las repeticiones de CGG tienden a expandirse, especialmente en la ovogénesis. Sin embargo, solo hasta que se excedan las 200 repeticiones que se presentará el síndrome, esta es la razón por la cual esta enfermedad no sigue rigurosamente el típico patrón de herencia ligada al X $(2,23)$.

Se estima que alrededor del mundo uno de cada 4000 hombres y una de cada 6000 mujeres padece el SFX, al presentar la mutación completa $(60,61)$. El estimado para las mutaciones parciales es uno por cada 130-200 hombres y uno por cada 250-450 mujeres $(53,62)$. Las personas con SFX, además de mostrar rasgos físicos característicos, como orejas grandes, cara alargada, estrabismo y testículos grandes, presentan discapacidad intelectual, alto déficit de atención (prevalencia del $80 \%$ ), problemas en el lenguaje, ansiedad e hiperactividad (incidencia del $66 \%$ ) (63). Una de las comorbilidades más asociadas al SFX es la epilepsia, aparte de que casi el $90 \%$ de los niños que sufren SFX tiene características autistas o sufre algún trastorno autista $(56,64)$.

En términos morfológicos, algunos estudios revelan que el volumen de los lóbulos corticales frontales y temporales en pacientes con SFX es menor que en pacientes sanos, y lo contrario ocurre con los lóbulos parietal y occipital, donde son significativamente mayores en el SFX. Se muestra, además, gran tamaño del núcleo caudado, y la reducción del tamaño del vermis cerebeloso posterior, la amígdala y el giro temporal superior en pacientes con SFX $(65,66)$. Histológicamente, las neuronas piramidales de la corteza cerebral de gran parte de estos pacientes muestran un mayor número de espinas dendríticas, que también son inmaduras y dismorfogénicas, lo que supone problemas en la plasticidad sináptica y da cuenta de muchos de los síntomas $(67,68)$. Estas observaciones confirman la importancia de la FMRP tanto en la fase de maduración como en la fase de eliminación de las sinapsis.

\section{Neuroliginas}

Las moléculas de adhesión neuronal sináptica son proteínas que conectan las membranas celulares de las neuronas implicadas en la sinapsis. Además de formar el marco estructural que define la hendidura sináptica, estas son específicas para cada fase de la sinaptogénesis, e incluso para cada tipo de membrana sea pre- o postsináptica. El deterioro funcional de alguna de estas moléculas es perjudicial para la función de la sinapsis (69). Dentro de este conjunto están las $\mathrm{Nlg}$, que participan en el complejo de adhesión neurexina$\mathrm{Nlg}$, fundamental en la fase de especialización sináptica.

La Nlg es una proteína transmembrana postsináptica que, con su dominio extracelular, se une a su contraparte presináptica, la proteína neurexina. Ambas proteínas tienen una región PDZ en su dominio citoplasmático que les permite unirse a proteínas del andamiaje celular que se anclan al citoesqueleto de la actina y les permite congregar proteínas a la densidad sináptica $(4,70)$. Estas proteínas promueven la especialización, sea pre- o postsináptica, de la neurona en la que se encuentran. Existen cuatro miembros en esta familia, las $\mathrm{Nlg} 1,2,3 \mathrm{y}$ 4. En el caso de la Nlg 1, hay evidencia de que su dominio PDZ recluta las proteínas necesarias para el ensamblaje de los receptores inotrópicos o metabotrópicos de glutamato en la membrana postsináptica $(71,72)$. Al contrario, se plantea que la Nlg 2 participa exclusivamente 
en sinapsis inhibitorias en el cerebro, debido a que recluta las proteínas que reúnen las subunidades de los receptores para GABA y glicina, independientemente de su dominio PDZ (71,73).

Ampliando la información anterior, se ha establecido que el dominio de densidad postsináptica de la Nlg 1 se une principalmente a la proteína de densidad postsináptica PSD-95 y a la proteína "molécula de andamiaje sináptico" (S-SCAM), las cuales pueden unirse a los receptores NMDA y AMPA y reclutarlos en la membrana postsináptica. Por su parte, la Nlg 2 se une a la proteína de andamiaje gefirina y a la proteína colibistina, que ayudan a reclutar a los receptores gabaérgicos de las sinapsis inhibitorias (71,74).

Las Nlg tienen una distribución específica en el cerebro: la $\mathrm{Nlg} 1$ se expresa exclusivamente dentro de las sinapsis excitatorias glutamatérgicas

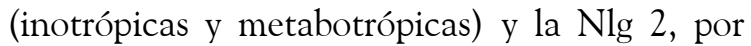
el contrario, preferentemente en las sinapsis inhibitorias gabaérgicas o colinérgicas. La Nlg 3 es capaz de localizarse en ambos tipos de sinapsis y la distribución de la $\mathrm{Nlg} 4$ es, en su mayoría, en sinapsis glicinérgicas; pero también se ha observado en sinapsis gabaérgicas, preponderantemente en la médula espinal y la retina $(69,71)$.

Es importante aclarar que aun cuando las Nlg son importantes para la especialización de la sinapsis, de ellas no depende la formación de estas, ya que en ratones triple $\mathrm{KO}$ para Nlg 1, 2 y 3 se demostró que se construían sinapsis, sin alteraciones en su número. Sin embargo, estas sinapsis presentaban problemas en su maduración y transmisión eléctrica, así como en la LTP (75). En ratones se ha encontrado que mutaciones en las $\mathrm{Nlg} 2$ llevan a un decrecimiento en las transmisiones gabaérgicas postsinápticas y, por lo tanto, a una alteración en la inhibición $(76,77)$.

Las $\mathrm{Nlg}$ forman homodímeros o heterodímeros obligatorios para cumplir su función (Nlg 1$\mathrm{Nlg}$ 1; Nlg 1-Nlg 3; Nlg 2-Nlg 2; Nlg 2-Nlg 3) o, a veces, agrupaciones de, al menos, cuatro entidades. Con este tipo de arreglos se cree que estas combinaciones aportan a la diversidad sináptica en el cerebro. Cabe resaltar que las $\mathrm{Nlg}$ son transportadas a la membrana postsináptica por tráfico vesicular y que ya en estas vesículas se cree que viajan dimerizadas $(71,78)$.

Las Nlg pueden sufrir cambios postraduccionales $y, \quad$ a su vez, estas modificaciones pueden ser promovidas por la actividad sináptica. La Nlg 1 es susceptible de ser fosforilada en su treonina 739 por la calmodulina cinasa 2 (CAMKII), lo que la hace más propensa a escisión o a que disminuya su expresión en la superficie de membrana postsináptica. Otra modificación interesante es la fosforilación casi constante de la $\mathrm{Nlg} 1$ en su tirosina 782, la cual impide la interacción de esta proteína con la gefirina (71). Se ha postulado que esta interacción se promueve justo en el momento en el que la Nlg 1 se une con la neurexina 1. También se han descrito fosforilaciones en la $\mathrm{Nlg}$ 2 que modulan su disposición a la asociación con la gefirina $(71,79)$. Se ha descrito también que las Nlg pueden ser glicosiladas y que esta modificación ayuda a la especialización de la proteína en su tipo de sinapsis; además, cuando esta modificación postraduccional es alterada, también lo hace la especificidad de la sinapsis $(79,80)$.

Se han encontrado mutaciones en los cromosomas que codifican para Nlgs en algunos pacientes con TEA. Dichas mutaciones se han asociado con el desequilibrio excitatorio/ inhibitorio característico del autismo y la epilepsia, donde se encuentran conexiones cerebrales menos inhibidas $(1,81,82)$. En ratones, la sobreexpresión y la eliminación de las $\mathrm{Nlg}$ lleva a deficiencias en la interacción social o la comunicación, a comportamientos repetitivos, a ansiedad y a problemas de aprendizaje y memoria $(83,84)$. En Drosophila, el $\mathrm{KO}$ de dnlg2 produce una disminución en los botones sinápticos, desarrollo aberrante de las uniones neuromusculares y una transmisión sináptica afectada; en tanto que los receptores de glutamato están disminuidos y hay una reducción de los potenciales de unión excitatoria. En pacientes con TEA se ha encontrado una mutación en $\mathrm{Nlg} 3$, diez mutaciones en $\mathrm{Nlg} 4$ y diferentes deleciones en el cromosoma $\mathrm{X}$, algunas 
de las cuales afectan el locus que codifica para $\mathrm{Nlg} 4(80,85)$. Estas mutaciones se han inducido en modelos animales murinos y se ha encontrado que afectan el tráfico de los receptores AMPA y la regulación de la transmisión sináptica excitatoria $(79,86)$.

Existen estudios que relacionan la ausencia de la FMRP con la expresión anormal de la proteína Nlg 1 y con déficits en el comportamiento social en ratones (5). Para reforzar esta relación, se ha comprobado que la FMRP se une a los ARNm de las Nlg 1, 2 y 3 en la sinapsis, y que regula negativamente su traducción en sinaptoneurosomas y en cultivos neuronales de ratón. Incluso se ha descrito que cuando se estimulan los receptores NMDA, hay una mayor asociación de $\mathrm{Nlg}$ a los polirribosomas, donde se potencia la traducción de estas proteínas; pero también existe una escisión proteolítica de las $\mathrm{Nlg} 1$ y 3 que ya se encuentran en la membrana, por lo que se ha propuesto de manera más contundente que las $\mathrm{Nlg}$ y su asociación con FMRP son dependientes de estimulación sensorial. En el estudio de Chmielewska et al. (87) se demostró, además, que en ratones $\mathrm{KO}$ para fmrl la cantidad de Nlg 1 y 3 expresadas en la membrana postsináptica aumenta como consecuencia de su elevada traducción.

Se han realizado experimentos en los que se induce LTP y LTD en neuronas del hipocampo en ratones y se ha mostrado un incremento y un decrecimiento, respectivamente, de la aparición de las Nlg 1 y 3 en la superficie de la membrana postsináptica. De esta manera, se plantea que la expresión de estas proteínas en la membrana celular es regulada por la actividad sináptica y también que su función aumenta o disminuye dependiendo de los estímulos aplicados (74). Estas observaciones explican cómo la actividad eléctrica, generada por la experiencia sensorial en las sinapsis, determina el estado de expresión de la familia de las $\mathrm{Nlg}$, proteínas necesarias para consolidar las fases de especialización y de maduración de las sinapsis.

\section{Drosophila melanogaster como modelo animal para el estudio de patologías relacionadas con FMRP y neuroliginas}

A pesar de que no existe ningún modelo animal que pueda reproducir el desarrollo de la expansión CGG en la UTR de sus ortólogos para el gen FMR1, en la mosca Drosophila melanogaster existe un gen ortólogo al FMR1 humano (dFMR1), con dominios idénticos en un $75 \%$ y con una similaridad del $85 \%$ que, incluso bioquímicamente y en cascadas celulares, se iguala a la función de la FMRP humana $(23,58,88)$. En la Drosophila melanogaster, la FMRP se expresa principalmente en el cerebro y la mutación para silenciar o escindir el gen dFMR1 genera un fenotipo que se asemeja el fenómeno del síndrome apreciado en mamíferos, desde su vía molecular hasta el desempeño comportamental, como lo han demostrado los resultados de las pruebas de memoria a largo plazo, de comportamiento de cortejo y del ritmo circadiano $(89,90,91)$.

Las uniones neuromusculares de $D$. melanogaster son sinapsis glutamatérgicas de neuronas motoras con membranas musculares que han servido para evidenciar fenómenos como la plasticidad neuronal y la transmisión sináptica, y donde la ausencia de FMRP produce un número excesivo de ramificaciones, botones sinápticos y una falta de focalización axonal (92). Igualmente, en el cuerpo de la seta (un gran circuito de neuronas que controlan el aprendizaje y la memoria olfatoria en la mosca) se ha descrito que las mutaciones que llevan a la eliminación de la FMRP cambian el remodelamiento y la morfología en las dendritas y los axones de las neuronas que lo componen. Más aún, en los individuos $\mathrm{KO}$ de $d f m r l$ se han documentado alteraciones en la relación de aversión y atracción de olores que se vinculan con modificaciones en las neuronas del glomérulo olfatorio. En el glomérulo se produce menos inhibición gabaérgica en las interneuronas que lo conectan a otros lóbulos del cerebro de la mosca (93).

La ventana restrictiva del desarrollo en este organismo comienza desde el final de la 
etapa de larva y abarca la etapa de pupa, la eclosión y la etapa de adulto-joven, que suman aproximadamente dos semanas (38). En esta ventana restrictiva se refinan los circuitos sensoriales que dan cuenta del proceso de aprendizaje y de plasticidad en el cerebro de la mosca y, por lo tanto, pueden dar bases robustas para entender molecularmente estos procesos en el cerebro humano (9).

En D. melanogaster se han descubierto proteínas importantes para comprender las bases moleculares del SFX. Recientemente, en este modelo se postuló que la proteína Wnd-DLK (Wallenda/cremallera doble de leucina cinasa), la cual es ortóloga de la MAPK3 (MAP cinasa 3, una proteína cuya vía se activa agudamente como respuesta a daños neuronales y crónicamente en enfermedades neurodegenerativas), es un factor importante para los perjuicios causados en el SFX. En el estudio de Russo y DiAntonio (94) se determinó que la dFMRP se une a Wnd y regula su traducción, limitando su expresión proteica. Por otro lado, en el mutante para dFRM1 null se encontró que las concentraciones de Wnd están anormalmente elevadas, produciendo en las moscas adultas una morfología irregular del cerebro, déficits en los comportamientos motores, de aprendizaje, de memoria y de sueño, al igual que los que se han encontrado en ratones knockout para este gen. Adicionalmente, se han encontrado defectos en las uniones neuromusculares en larvas mutadas en dFRM1. Al aplicarle inhibidores orales de mamíferos para $\mathrm{WnD} / \mathrm{DLK}$ a este organismo modelo invertebrado, se ha vuelto a recuperar el normotipo en la morfología y transmisión sináptica y en el comportamiento de las moscas y larvas, postulando a la inhibición de la vía MAP cinasas-WnD/DLK como una posible estrategia terapéutica contra los efectos del SFX (94).

El genoma de D. melanogastertambién codifica para cuatro tipos de Nlg. Estas, sin embargo, se ubican de forma diferente a los humanos y a los murinos. En D. melanogaster las Nlg 1 y 3 (DNlg 1 y 3) se encuentran preferentemente en uniones neuromusculares $(95,96)$; mientras que la DNlg 2 se ubica tanto en uniones neuromusculares como en el sistema nervioso central (de manera abundante en el cuerpo de la seta y en el complejo central), y la DNlg 4 se postula que se ubica en las grandes neuronas del reloj ventral de las moscas $(97,98)$.

Se ha encontrado que en la Drosophila, las DNlg 1, 2 y 3 actúan tanto en terminales pre- como postsinápticas, de una manera preferentemente excitatoria. En cambio, la DNlg4 se ha relacionado con sinapsis gabaérgicas (98). De esta manera, se puede decir que estos cuatro genes de Drosophila no tienen una similaridad funcional exacta con la de los cuatro genes de Nlg mamíferas. No obstante, en su función más general (la de unir y especializar las sinapsis) sí se encuentra una correspondencia con su papel en mamíferos (93).

Consecuentemente con lo anterior, se ha documentado en la Drosophila melanogaster que las mutaciones en DNlg 2 reducen tanto el árbol axonal como los botones sinápticos y alteran las cantidades de transmisores liberados en las uniones neuromusculares $(96,99)$. También se ha encontrado que las mutaciones en DNlg 1 y 3 llevan a una reducción de la maduración sináptica y de los botones sinápticos en las uniones neuromusculares, así como a problemas en la diferenciación sináptica $(11,97,98)$. Adicionalmente, se ha comprobado que la ausencia de DNlg 2 y 4 altera las interacciones sociales de las moscas (98).

\section{Conclusiones}

Las proteínas FMRP y las Nlg han sido ampliamente estudiadas en contextos aislados con referencia a su participación en los procesos propios del desarrollo del sistema nervioso, y así se ha demostrado su rol activo durante aquellos fenómenos plásticos dependientes de actividad sensorial, durante los periodos críticos posnatales. Se conocen aspectos de su estructura molecular, de la regulación de su expresión, de la distribución en los tejidos y de su participación en cascadas específicas de señalización e interacciones previamente descritas en el texto, y aun así es importante ampliar su panorama general. Por ejemplo, los estudios que permiten 
entender la interacción de estas proteínas entre ellas son más limitados, a pesar de que a ambos tipos proteicos se les relaciona con los procesos de plasticidad durante periodos críticos y también con alteraciones en patologías del desarrollo como SFX y TEA. Por esto, a pesar de que parecen participar en cascadas similares (como describimos en el texto), y aunque hay algunos datos sobre la relevancia funcional de sus posibles interacciones moleculares o dinámicas funcionales dependientes, la relación entre estas dos clases de proteínas debe explorarse a profundidad y todavía es un campo abierto.

Al contar con homólogos de estas proteínas, al ser Drosophila melanogaster un organismo pequeño, y al ser fácil de manipular y cruzar genéticamente, con una tasa reproductiva alta, es un organismo ideal para iniciar este tipo de estudios en laboratorios en países en vías de desarrollo, sin el temor de no poder traducir los hallazgos a mamíferos. En este organismo se pueden resolver futuras preguntas como: ipuede un protocolo experimental de estímulos sensoriales ayudar a alterar o modificar la relación FMRP-Nlg en el cerebro de un organismo en su etapa posnatal? iPuede el ARN de interferencia modificar la unión de la FMRP a la Nlg dependiendo de la LTD o la LTP? ¿Puede la FMRP llegar a modular no solo la traducción de las Nlg, sino también su transcripción, como una regulación epigenética? Preguntas como estas revelan lo mucho que falta por ser estudiado; pero lo cierto es que Drosophila melanogaster es un excelente modelo para empezar a resolver dichos interrogantes.

\section{Conflicto de intereses}

Declaramos que no existe un conflicto de interés para ninguno de los autores en esta revisión de tema.

\section{Agradecimientos}

Nuestras fuentes de financiación fueron: un premio internacional que apoya ideas para colaboraciones nuevas llamado The Women in World Neurosciences (WWN) Collaborative Research Network Program (CRNP) Award 2014, financiado por IBRO/SfN, y las convocatorias internas de investigación de las Universidades Icesi y la Pontificia Universidad Javeriana de Cali.

\section{Referencias}

1. Gilbert J, Man H-Y. Fundamental elements in autism: from neurogenesis and neurite growth to synaptic plasticity. Front Cell Neurosci [Internet]. 2017 Nov 20;11:1-25. https://doi.org/10.3389/fncel.2017.00359

2. Jin P. Understanding the molecular basis of fragile X syndrome. Hum Mol Genet. 2000 Apr 1;9(6):901-8. https://doi.org/10.1093/ hmg/9.6.901

3. Booker SA, Domanski APF, Dando OR, Jackson AD, Isaac JTR, Hardingham GE, et al. Altered dendritic spine function and integration in a mouse model of fragile $\mathrm{X}$ syndrome. Nat Commun. 2019 Dec 23;10(1):4813. http://dx.doi.org/10.1038/s 41467-019-11891-6

4. Craig AM, Kang Y. Neurexin-neuroligin signaling in synapse development. Curr Opin Neurobiol. 2007;17(1):43-52.

5. Dahlhaus R, El-Husseini A. Altered neuroligin expression is involved in social deficits in a mouse model of the fragile $\mathrm{X}$ syndrome. Behav Brain Res. 2010 Mar;208(1):96-105. http://dx.doi.org/10.1 016/j.bbr.2009.11.019

6. Darnell JC, Van Driesche SJ, Zhang C, Hung KYS, Mele A, Fraser CE, et al. FMRP stalls ribosomal translocation on mRNAs linked to synaptic function and autism. Cell. 2011 Jul 22;146(2):247-61. http://dx.doi.org/10. 1016/j.cell.2011.06.013

7. Selemon LD. A role for synaptic plasticity in the adolescent development of executive function. Transl Psychiatry. 2013 Mar;3(3):e238-e238.

8. Riccomagno MM, Kolodkin AL. Sculpting neural circuits by axon and dendrite 
pruning. Annu Rev Cell Dev Biol. 2015 Nov;31(1):779-805.

9. Doll CA, Broadie K. Impaired activitydependent neural circuit assembly and refinement in autism spectrum disorder genetic models. Front Cell Neurosci. 2014;8(February):30. https://doi.org/10.33 89/fncel.2014.00030

10. Tessier CR, Broadie K. Activitydependent modulation of neural circuit synaptic connectivity. Front Mol Neurosci. 2009;2(July):8.

11. Millán AP, Torres JJ, Marro J. How memory conforms to brain development. Front Comput Neurosci [Internet]. 2019 Apr 16;13:1-17. https://doi.org/10.3389/fncom. 2019.00022

12. Melom JE, Littleton JT. Synapse development in health and disease. Curr Opin Genet Dev. 2011 Jun;21(3):256-61. http://dx.doi. org/10.1016/j.gde.2011.01.002

13. Abraham WC, Jones OD, Glanzman DL. Is plasticity of synapses the mechanism of long-term memory storage? NPJ Sci Learn. 2019 Dec 2;4(1):9. http://dx.doi.org/10.10 38/s41539-019-0048-y

14. Wiegert JS, Oertner TG. Long-term depression triggers the selective elimination of weakly integrated synapses. Proc Natl Acad Sci. 2013 Nov 19;110(47): E4510-9. https://doi.org/10.1073/pnas.1315926110

15. Kang SJ, Kaang B-K. Metabotropic glutamate receptor dependent long-term depression in the cortex. Korean J Physiol Pharmacol. 2016;20(6):557. https://doi.org/10.4196/kj pp.2016.20.6.557

16. Hanley JG. The regulation of AMPA receptor endocytosis by dynamic protein-protein interactions. Front Cell Neurosci. 2018 Oct 11;12:1-10. https://doi.org/10.3389/fncel.2 018.00362

17. Gladding CM, Fitzjohn SM, Molnár E. Metabotropic glutamate receptormediated long-term depression: molecular mechanisms. Pharmacol Rev. 2009 Dec;61(4):395-412. https://doi.org/10.112 4/pr.109.001735
18. Collingridge GL, Peineau S, Howland JG, Wang YT. Long-term depression in the CNS. Nat Rev Neurosci [internet]. 2010 Jul;11(7):459-73. Disponible en: http://ww w.nature.com/articles/nrn2867

19. Maffei A. Long-term potentiation and long-term depression. En: Oxford research encyclopedia of neuroscience [internet]. Oxford: Oxford University Press; 2018. p. 1-31. Disponible en: https://oxfordre.com/neuroscience/vie w/10.1093/acrefore/9780190264086.001.0 001/acrefore-9780190264086-e-148

20. Bear MF, Huber KM, Warren ST. The mGluR theory of fragile $\mathrm{X}$ mental retardation. Trends Neurosci. 2004;27(7):370-7.

21. Sidorov MS, Auerbach BD, Bear MF. Fragile $\mathrm{X}$ mental retardation protein and synaptic plasticity. 2013;1-11.

22. Gholizadeh S, Halder SK, Hampson DR. Expression of fragile $\mathrm{X}$ mental retardation protein in neurons and glia of the developing and adult mouse brain. Brain Res. 2015;1596:22-30. http://dx.doi.org/10 .1016/j.brainres.2014.11.023

23. Santoro MR, Bray SM, Warren ST. Molecular Mechanisms of Fragile X Syndrome: A Twenty-Year Perspective. Annu Rev Pathol Mech Dis. 2012 Feb 28;7(1):219-45. Disponible en: https://doi.org/10.1146/ann urev-pathol-011811-132457

24. D'Annessa I, Cicconardi F, Di Marino D. Handling FMRP and its molecular partners: Structural insights into Fragile $\mathrm{X}$ Syndrome. Prog Biophys Mol Biol. 2019;141:3-14. https://doi.org/10.1016/j.pb iomolbio.2018.07.001

25. Chen E, Sharma MR, Shi X, Agrawal RK, Joseph S. Fragile X Mental retardation protein regulates translation by binding directly to the ribosome. Mol Cell. 2014 May;54(3):407-17. https://doi.org/10.1016/ j.conb.2009.03.011

26. Bartholomay K, Lee C, Bruno J, Lightbody A, Reiss A. Closing the gender gap in fragile $\mathrm{X}$ syndrome: review on females with FXS and preliminary research findings. Brain 
Sci. 2019 Jan 12;9(1):11. https://doi.org/10 $.3390 /$ brainsci9010011

27. Kenny P, Ceman S. RNA secondary structure modulates FMRP's bi-functional role in the microRNA pathway. Int J Mol Sci. 2016 Jun 22;17(6):985. https://doi.org/10.3390/i jms17060985

28. Banerjee A, Ifrim MF, Valdez AN, Raj N, Bassell GJ. Aberrant RNA translation in fragile $\mathrm{X}$ syndrome: From FMRP mechanisms to emerging therapeutic strategies. Brain Res. 2018 Aug;1693:24-36. https://doi.org/10.1016/j. brainres.2018.04.008

29. Abekhoukh S, Sahin HB, Grossi M, Zongaro S, Maurin T, Madrigal I, et al. New insights into the regulatory function of CYFIP1 in the context of WAVE- and FMRPcontaining complexes. Dis Model Mech. 2017 Apr 1;10(4):463-74. https://doi.org/1 0.1242/dmm.025809

30. Dury AY, El Fatimy R, Tremblay S, Rose TM, Côté J, De Koninck P, et al. Nuclear fragile $\mathrm{X}$ mental retardation protein is localized to cajal bodies. PLoS Genet. 2013;9(10).

31. Kim M, Bellini M, Ceman S. Fragile X mental retardation protein FMRP binds mRNAs in the nucleus. Mol Cell Biol. 2009;29(1):214-28.

32. Alpatov R, Lesch BJ, Nakamoto-Kinoshita M, Blanco A, Chen S, Stützer A, et al. A Chromatin-dependent role of the fragile $\mathrm{X}$ mental retardation protein FMRP in the DNA damage response. Cell. 2014 May;157(4):869-81. https://doi.org/10.101 6/j.cell.2014.03.040

33. Denman RB, Dolzhanskaya N, Sung YJ. Regulating a translational regulator: mechanisms cells use to control the activity of the fragile $\mathrm{X}$ mental retardation protein. Cell Mol Life Sci. 2004 Jul;61(14):1714-28. https://doi.org/10.100 7/s00018-004-4059-2

34. Ceman S, O'Donnell WT, Reed M, Patton S, Pohl J, Warren ST. Phosphorylation influences the translation state of FMRPassociated polyribosomes. Hum Mol Genet.
2003 Dec 15;12(24):3295-305. https://doi. org $/ 10.1093 / \mathrm{hmg} / \mathrm{ddg} 350$

35. Narayanan U, Nalavadi V, Nakamoto M, Thomas G, Ceman S, Bassell GJ, et al. S6K1 phosphorylates and regulates fragile $\mathrm{X}$ mental retardation protein (FMRP) with the neuronal protein synthesis-dependent mammalian target of rapamycin (mTOR) signaling cascade. J Biol Chem. $2008 \mathrm{Jul}$ 4;283(27):18478-82. https://doi.org/10.107 4/jbc.C800055200

36. Dolzhanskaya N. Methylation regulates the intracellular protein-protein and proteinRNA interactions of FMRP. J Cell Sci. 2006 May 1;119(9):1933-46. https://doi.org/10.1 $242 /$ jcs.02882

37. Singh K, Gaur P, Prasad S. Fragile X mental retardation (Fmr-1) gene expression is down regulated in brain of mice during aging. Mol Biol Rep [internet]. 2007 Sep;34(3):173-81. https://doi.org/10.1007/ s11033-006-9032-8

38. Tessier CR, Broadie K. Drosophila fragile $\mathrm{X}$ mental retardation protein developmentally regulates activitydependent axon pruning. Development. 2008 Apr;135(8):1547-57. https://doi.org/1 $0.1242 / \mathrm{dev} .015867$

39. Irwin SA, Christmon CA, Grossman AW, Galvez R, Kim SH, DeGrush BJ, et al. Fragile X mental retardation protein levels increase following complex environment exposure in rat brain regions undergoing active synaptogenesis. Neurobiol Learn Mem. 2005;83(3):180-7.

40. Tsang B, Arsenault J, Vernon RM, Lin $\mathrm{H}$, Sonenberg N, Wang L-Y, et al. Phosphoregulated FMRP phase separation models activity-dependent translation through bidirectional control of mRNA granule formation. Proc Natl Acad Sci. 2019 Mar 5;116(10):4218-27. https://doi.o rg/10.1073/pnas.1814385116

41. Iliff AJ, Renoux AJ, Krans A, Usdin KU, Sutton MA, Todd PK. Impaired activity-dependent FMRP translation and enhanced mGluR-dependent LTD in 
Elisa Viveros Araque, Juliana Rengifo Gómez, Lina Becerra.

fragile $\mathrm{X}$ premutation mice. Hum $\mathrm{Mol}$ Genet. 2013;22(6):1180-92.

42. Nolze A, Schneider J, Keil R, Lederer M, Hüttelmaier S, Kessels MM, et al. FMRP regulates actin filament organization via the armadillo protein p0071. RNA. 2013;19(11):1483-96. https://doi.org/10.12 61/rna.037945.112

43. Zhang P, Abdelmohsen K, Liu Y, TominagaYamanaka K, Yoon J-H, Ioannis $G$, et al. Novel RNA- and FMRP-binding protein TRF2-S regulates axonal mRNA transport and presynaptic plasticity. Nat Commun. 2015;6:8888. https://doi.org/10.1038/ncom ms 9888

44. Pfeiffer BE, Zang T, Wilkerson JR, Taniguchi M, Maksimova MA, Smith LN, et al. Fragile $\mathrm{X}$ mental retardation protein is required for synapse elimination by the activitydependent transcription factor MEF2. Neuron. 2010;66(2):191-7. http://dx.doi.or g/10.1016/j.neuron.2010.03.017

45. Waung MW, Huber KM. Protein translation in synaptic plasticity: mGluRLTD, Fragile X. Curr Opin Neurobiol. 2009 Jun;19(3):319-26. https://doi.org/10.1016/j .conb.2009.03.011

46. Cook D, Cameron S a, Jones E V. Fragile $\mathrm{X}$ Mental retardation protein: regulator of specific mRNAs or master regulator of global translation? J Neurosci. 2010 May 26;30(21):7121-3. https://doi.org/10.1523/ JNEUROSCI.1298-10.2010

47. Wang $\mathrm{H}$. Fragile $\mathrm{X}$ mental retardation protein: from autism to neurodegenerative disease. Front Cell Neurosci [internet]. 2015 Feb 12;9(feb):7. Disponible en: http://journal.frontiersin.org/Article/10 $.3389 /$ fncel.2015.00043/abstract

48. Xing Z, Zeng M, Hu H, Zhang H, Hao Z, Long $\mathrm{Y}$, et al. Fragile X mental retardation protein promotes astrocytoma proliferation via the MEK/ERK signaling pathway. Oncotarget [internet]. 2016 Nov 15;7(46):75394-406. Disponible en: http://www.oncotarget.com /fulltext/12215

49. Kim SH, Markham JA, Weiler IJ, Greenough WT. Aberrant early-phase ERK inactivation impedes neuronal function in fragile X syndrome. Proc Natl Acad Sci. 2008 Mar 18;105(11):4429-34. https://doi. org/10.1073/pnas.0800257105

50. Cruz-Martin A, Crespo M, Portera-Cailliau C. Delayed stabilization of dendritic spines in fragile X mice. J Neurosci. 2010 Jun 9;30(23):7793-803. https://doi.org/10.1523 /JNEUROSCI.0577-10.2010

51. Abbeduto L, McDuffie A, Thurman AJ. The fragile $\mathrm{x}$ syndrome-autism comorbidity: What do we really know? Front Genet. 2014;5 (SEP):1-10.

52. Niu M, Han Y, Dy ABC, Du J, Jin H, Qin J, et al. Autism symptoms in fragile $\mathrm{X}$ syndrome. J Child Neurol. 2017 Sep;32(10):903-9.

53. Ciaccio C, Fontana L, Milani D, Tabano S, Miozzo M, Esposito S. Fragile X syndrome: a review of clinical and molecular diagnoses. Ital J Pediatr. 2017 Dec 19;43(1):39. https: //doi.org/10.1186/s13052-017-0355-y

54. Verkerk AJMH, Pieretti M, Sutcliffe JS, Fu Y-H, Kuhl DPA, Pizzuti A, et al. Identification of a gene (FMR-1) containing a CGG repeat coincident with a breakpoint cluster region exhibiting length variation in fragile $\mathrm{X}$ syndrome. Cell [internet]. 1991 May;65(5):905-14. Disponible en: http://linkinghub.elsevier.co m/retrieve/pii/009286749190397H

55. Kumari D, Gazy I. Towards mechanism-based treatments for fragile $\mathrm{X}$ syndrome. Brain Sci. 2019 Aug 16;9(8):202. https://doi.org/ 10.3390/brainsci9080202

56. Devitt N, Gallagher L, Reilly R. Autism Spectrum Disorder (ASD) and Fragile X Syndrome (FXS): two overlapping disorders reviewed through electroencephalography_what can be interpreted from the available information? Brain Sci. 2015 Mar 27;5(2):92-117. https: //doi.org/10.3390/brainsci5020092

57. Baker EK, Arpone M, Aliaga SM, Bretherton L, Kraan CM, Bui M, et al. Incomplete silencing of full mutation alleles in males with fragile $\mathrm{X}$ syndrome is associated with autistic features. Mol Autism. 2019 Dec 
3;10(1):21. https://doi.org/10.1186/s13229 $-019-0271-7$

58. Drozd M, Bardoni B, Capovilla M. Modeling Fragile $\mathrm{X}$ syndrome in drosophila. Front Mol Neurosci. 2018 Apr 16;11(April):1-15. https://doi.org/10.3389/ fnmol.2018.00124/full

59. Li Y, Stockton ME, Eisinger BE, Zhao Y, Miller JL, Bhuiyan I, et al. Reducing histone acetylation rescues cognitive deficits in a mouse model of Fragile X syndrome. Nat Commun. 2018 Dec 27;9(1):2494. http://d x.doi.org/10.1038/s41467-018-04869-3

60. Hagerman PJ. The fragile $X$ prevalence paradox. J Med Genet. 2008 Aug;45(8):498-9. https://doi.org/10.1136/j mg.2008.059055

61. Wall CA, Hogan AL, Will EA, McQuillin S, Kelleher BL, Roberts JE. Early negative affect in males and females with fragile $\mathrm{X}$ syndrome: implications for anxiety and autism. J Neurodev Disord. 2019 Dec 13;11(1):22. https://doi.org/10.1186/s1168 9-019-9284-y

62. Crawford H, Moss J, Anderson GM, Oliver C, McCleery JP. Implicit discrimination of basic facial expressions of positive/negative emotion in fragile $\mathrm{X}$ syndrome and autism spectrum disorder. Am J Intellect Dev Disabil. 2015 Jul;120(4):328-45. https://do i.org/10.1352/1944-7558-120.4.328

63. Tejada MI. Síndrome X frágil: libro de consulta para familias y profesionales. Vol. 140. Madrid: Real Patronato sobre Discapacidad; 2006.

64. Christensen DL, Baio J, Braun KVN, Bilder D, Charles J, Constantino JN, et al. Prevalence and characteristics of autism spectrum disorder among children aged 8 years - autism and developmental disabilities monitoring network, 11 sites, United States, 2012. MMWR Surveill Summ [internet]. 2016;65(3):1-23. Disponible en: http://www.cdc.gov/mmwr/ volumes/65/ss/ss6503a1.htm

65. Gothelf D, Furfaro JA, Hoeft F, Eckert MA, Hall SS, O'Hara R, et al. Neuroanatomy of fragile $\mathrm{X}$ syndrome is associated with aberrant behavior and the fragile X mental retardation protein (FMRP). Ann Neurol. 2008 Jan;63(1):40-51. https://doi.org/10.10 02/ana.21243

66. Salcedo-Arellano MJ, Dufour B, McLennan Y, Martinez-Cerdeno V, Hagerman R. Fragile X syndrome and associated disorders: clinical aspects and pathology. Neurobiol Dis. 2020 Mar;136:104740. https://doi.org/10.10 16/j.nbd.2020.104740

67. McCann RF, Ross DA. A fragile balance: dendritic spines, learning, and memory. Biol Psychiatry. 2017 Jul;82(2):e11-3. http://dx. doi.org/10.1016/j.biopsych.2017.05.020

68. Telias M. Molecular mechanisms of synaptic dysregulation in fragile $\mathrm{X}$ syndrome and autism spectrum disorders. Front $\mathrm{Mol}$ Neurosci. 2019 Mar 7;12. https://doi.org/1 0.3389/fnmol.2019.00051

69. Missler M, Südhof TC, Biederer T. Synaptic cell adhesion. Cold Spring Harb Perspect Biol. 2012 Apr;4(4):a005694. https://doi.o $\mathrm{rg} / 10.1101 / \mathrm{cshperspect.a005694}$

70. Lisé MF, El-Husseini A. The neuroligin and neurexin families: From structure to function at the synapse. Cell Mol Life Sci. 2006;63(16):1833-49.

71. Bemben MA, Shipman SL, Nicoll RA, Roche KW. The cellular and molecular landscape of neuroligins. Trends Neurosci. 2015 Aug;38(8):496-505. http://dx.doi.org /10.1016/j.tins.2015.06.004

72. Danielson E, Zhang N, Metallo J, Kaleka K, Shin SM, Gerges N, et al. S-SCAM/MAGI-2 Is an essential synaptic scaffolding molecule for the GluA2-containing maintenance pool of AMPA receptors. J Neurosci. 2012 May 16;32 (20):6967-80. https://doi.org/10.1523 /JNEUROSCI.0025-12.2012

73. Poulopoulos A, Aramuni G, Meyer G, Soykan T, Hoon M, Papadopoulos T, et al. Neuroligin 2 drives postsynaptic assembly at perisomatic inhibitory synapses through gephyrin and collybistin. Neuron. 2009 Sep 
10;63(5):628-42. https://doi.org/10.1016/j. neuron.2009.08.023

74. Hu X, Luo J, Xu J. The interplay between synaptic activity and neuroligin function in the CNS. Biomed Res Int. 2015;2015:1-13. https://doi.org/10.1155/2015/498957

75. Shaw HS, Salmon CK. Refining the roles of neuroligins in synapse development and function: a reductionist conditional knock-out approach. J Neurosci. 2017 Dec 6;37 (49):11769-71. https://doi.org/10.1523 /JNEUROSCI.2492-17.2017

76. Lozano R, Hare EB, Hagerman RJ. Modulation of the GABAergic pathway for the treatment of fragile $\mathrm{X}$ syndrome. 2014;1769-79.

77. Verma V, Paul A, Amrapali Vishwanath A, Vaidya B, Clement JP. Understanding intellectual disability and autism spectrum disorders from common mouse models: synapses to behaviour. Open Biol. 2019 Jun 28;9(6):180265. https://doi.org/10.109 8/rsob.180265

78. Poulopoulos A, Soykan T, Tuffy LP, Hammer M, Varoqueaux F, Brose N. Homodimerization and isoform-specific heterodimerization of neuroligins. Biochem J. 2012 Sep 1;446(2):321-30. https://doi.or $\mathrm{g} / 10.1042 / \mathrm{BJ} 20120808$

79. Jeong J, Paskus JD, Roche KW. Posttranslational modifications of neuroligins regulate neuronal and glial signaling. Curr Opin Neurobiol. 2017 Aug;45(5):130-8. https://doi.org/10.1016/j. conb.2017.05.017

80. Marzena Q, Mordalska P, We K. Neuroligins, synapse balance and neuropsychiatric disorders. Pharmacol Rep. 2014;66(5):830-5. https://doi.org/10.1016/j .pharep.2014.04.011

81. Dean C, Dresbach T. Neuroligins and neurexins: linking cell adhesion, synapse formation and cognitive function. Trends Neurosci [internet]. 2006 Jan;29(1):21-9. Disponible en: https://inkinghub.elsevier.c om/retrieve/pii/S0166223605003000

82. Uzunova G, Pallanti S, Hollander E. Excitatory/inhibitory imbalance in autism spectrum disorders: Implications for interventions and therapeutics. World J Biol Psychiatry. 2016 Apr;17(3):174-86. https://doi.org/10.3109/ 15622975.2015.1085597

83. Norris RHC, Churilov L, Hannan AJ, Nithianantharajah J. Mutations in neuroligin-3 in male mice impact behavioral flexibility but not relational memory in a touchscreen test of visual transitive inference. Mol Autism. $2019 \mathrm{Dec}$ 2;10(1):42. https://doi.org/10.1186/s13229 $-019-0292-2$

84. Blundell J, Blaiss CA, Etherton MR, Espinosa F, Tabuchi K, Walz C, et al. Neuroligin-1 deletion results in impaired spatial memory and increased repetitive behavior. J Neurosci. 2010;30(6):2115-29.

85. Zhang B, Gokce O, Hale WD, Brose N, Südhof TC. Autism-associated neuroligin-4 mutation selectively impairs glycinergic synaptic transmission in mouse brainstem synapses. 2018;215(6):1543-53. https://doi .org/10.1084/jem.20172162

86. Marro SG, Chanda S, Yang N, Janas JA, Valperga G, Trotter J, et al. Neuroligin-4 regulates excitatory synaptic transmission in human neurons. Neuron. 2019 Aug;103(4):617-626.e6. https://doi.o $\mathrm{rg} / 10.1016 /$ j.neuron.2019.05.043

87. Chmielewska JJ, Kuzniewska B, Milek J, Urbanska K, Dziembowska M. Neuroligin 1, 2, and 3 Regulation at the Synapse: FMRP-Dependent Translation and Activity-Induced Proteolytic Cleavage. Mol Neurobiol. 2019;56(4):2741-59.

88. Bakker CE, Oostra BA. Understanding fragile $\mathrm{X}$ syndrome: insights from animal models. Cytogenet Genome Res [internet]. 2003;100(1-4):111-23. Disponible en: https://www.karger.com/Art icle/FullText/72845

89. Zhang YQ, Broadie K. Fathoming fragile $\mathrm{X}$ in fruit flies. Trends Genet. 2005 Jan;21(1):37-45. https://doi.org/10.1016/j.t ig.2004.11.003

90. Wan L, Dockendorff TC, Jongens T, Dreyfuss G. Characterization of 
dFMR1, a Drosophila melanogaster homolog of the fragile $X$ mental retardation protein. Mol Cell Biol. 2000 Nov;20(22):8536-47. https://doi.org/10.11 28/mcb.20.22.8536-8547.2000

91. Mosca TJ, Carrillo RA, White BH, Keshishian H. Dissection of synaptic excitability phenotypes by using a dominant-negative Shaker $\mathrm{K}+$ channel subunit. Proc Natl Acad Sci U S A. 2005 Mar 1;102(9):3477-82. https://doi.org/10.1 073/pnas.0406164102

92. Tian Y, Zhang ZC, Han J. Drosophila studies on autism spectrum disorders. Neurosci Bull . 2017 Dec 9;33(6):737-46. https://doi .org/10.1007/s12264-017-0166-6

93. Bellosta P, Soldano A. Dissecting the genetics of autism spectrum disorders: a drosophila perspective. Front Physiol. 2019 Aug 7;10(JUL):1-8. https://doi.org/10.3389 /fphys.2019.00987/full

94. Russo A, DiAntonio A. Wnd/ DLK Is a Critical Target of FMRP responsible for neurodevelopmental and behavior defects in the drosophila model of fragile $\mathrm{X}$ syndrome. Cell Rep. 2019;28(10):2581-2593.e5. https://doi.org/ 10.1016/j.celrep.2019.08.001

95. Banovic D, Khorramshahi O, Owald D, Wichmann C, Riedt T, Fouquet W, et al. Drosophila neuroligin 1 promotes growth and postsynaptic differentiation at glutamatergic neuromuscular junctions. Neuron. 2010 Jun 10;66(5):724-38. http:// dx.doi.org/10.1016/j.neuron.2010.05.020

96. Xing G, Gan G, Chen D, Sun M, Yi J, Lv $\mathrm{H}$, et al. Drosophila neuroligin3 regulates neuromuscular junction development and synaptic differentiation. J Biol Chem. 2014 Nov 14;289(46):31867-77. https://doi.org/ 10.1074/jbc.M114.574897

97. Sun M, Xing G, Yuan L, Gan G, Knight D, With SI, et al. Neuroligin 2 is required for synapse development and function at the Drosophila neuromuscular junction. J Neurosci. 2011 Jan 12;31(2):687-99. https://doi.org/10.152 3/JNEUROSCI.3854-10.2011
98. Corthals K, Heukamp AS, Kossen R, Großhennig I, Hahn N, Gras H, et al. Neuroligins $\mathrm{Nlg} 2$ and Nlg4 affect social behavior in drosophila melanogaster. Front Psychiatry. 2017 Jul 10;8(jul). https://doi.or g/10.3389/fpsyt.2017.00113/full

99. Chen Y-C, Lin YQ, Banerjee S, Venken $\mathrm{K}, \mathrm{Li} \mathrm{J}$, Ismat $\mathrm{A}$, et al. Drosophila neuroligin 2 is required presynaptically and postsynaptically for proper synaptic differentiation and synaptic transmission. J Neurosci. 2012 Nov 7;32(45):16018-30. https://doi.org/10.1523 /JNEUROSCI.3854-10.2011 